\title{
A case of transplantation-associated thrombotic microangiopathy with autopsy-proven fatal myocardial ischemia after allogeneic hematopoietic stem cell transplantation
}

\author{
Ken Sasaki $^{1}$ - Akira Honda ${ }^{1}$ - Aya Shinozaki-Ushiku ${ }^{2} \cdot$ Yosei Fujioka $^{1} \cdot$ Hiroaki Maki $^{1}$ - Kazuhiro Toyama ${ }^{1}$. \\ Tetsuo Ushiku² ${ }^{2}$ Mineo Kurokawa ${ }^{1,3}$
}

Received: 6 March 2020 / Accepted: 10 April 2020 / Published online: 6 May 2020

(C) The Author(s) 2020

\section{Dear Editor,}

Hematopoietic stem cell transplantation-associated thrombotic microangiopathy (TA-TMA) is one of the most severe complications after allogeneic hematopoietic stem cell transplantation (HSCT) [1,2]. Although TA-TMA commonly affects kidneys, lungs, and the gastrointestinal tract, only one case of TA-TMA with cardiac involvement has been reported. In this report, limited cardiac involvement was proven by autopsy, but it was not the main cause of death [3]. Herein, we report a first case of fatal myocardial ischemia caused by TA-TMA proven by autopsy.

A 59-year-old female underwent allogeneic HSCT from an HLA 8/8 matched unrelated donor with non-myeloablative conditioning for AML. She developed chronic graft-versushost disease 9 months after transplant. During the treatment with prednisolone and cyclosporin (CyA), she was diagnosed with TA-TMA based on the findings of thrombocytopenia $\left(7.4 \times 10^{4} / \mu \mathrm{L}\right)$, anemia $(10.3 \mathrm{~g} / \mathrm{dL})$, schistocytes $(20-25 /$ $\mathrm{HPF})$, elevated lactate dehydrogenase (LDH) (874 IU/L), and decreased haptoglobin $(3 \mathrm{mg} / \mathrm{dL})$. Despite the cessation of CyA, she noticed the exacerbation of the shortness of breath and the edema of both legs. Echocardiography showed

Mineo Kurokawa

kurokawa-tky@umin.ac.jp

1 Department of Hematology and Oncology, Graduate School of Medicine, The University of Tokyo, 7-3-1 Hongo, Bunkyo-ku, Tokyo 113-8655, Japan

2 Department of Pathology, Graduate School of Medicine, The University of Tokyo, 7-3-1 Hongo, Bunkyo-ku, Tokyo 113-8655, Japan

3 Department of Cell Therapy and Transplantation Medicine, The University of Tokyo Hospital, 7-3-1 Hongo, Bunkyo-ku, Tokyo 113-8655, Japan reduced ejection fraction (EF 23\%) and global hypokinesis. Right ventricular systolic pressure (RVSP) was not elevated (23 $\mathrm{mmHg}$ ). The blood tests showed the elevated troponin T $(0.227 \mathrm{ng} / \mathrm{mL})$ and the elevated BNP $(1770.6 \mathrm{pg} / \mathrm{mL})$, but did not show the elevation of creatine kinase (CK $108 \mathrm{U} / \mathrm{L})$ or CK-MB (12 U/L). Electrocardiogram showed inverted T waves in leads I, II, and V3-6. Coronary angiography and biopsy could not be done because of severe thrombocytopenia. Then, her cardiac dysfunction was exacerbated, and she died after sudden cardiac arrest despite the treatment.

An autopsy revealed the dilation of the left ventricle and fibrosis on the anterior and posterior wall of the left ventricle of the heart (Fig. 1a). Microscopic examination revealed fibrosis with edema and dilated capillaries on the anterior, posterior, and lateral walls. It also showed the intimal thickening and the narrowing of the lumen of the arterioles and the organized thrombus in the distal part of the left anterior descending artery, which suggest the involvement of TA-TMA (Fig. 1bd). Based on these findings, we concluded that the cause of death was myocardial ischemia due to TA-TMA. There were no signs of relapse of AML.

Cardiac complications after HSCT have been reported previously, and they are most likely to be caused by the conditioning regimens $[4,5]$. Only one case of cardiac involvement of TA-TMA has been reported, in which TA-TMA was not the main cause of death [3]. In the present case, we experienced a first case of fatal myocardial ischemia caused by TA-TMA. As the present case suggests, myocardial ischemia caused by TATMA may not be reversible by the withdrawal of calcineurin inhibitors even when other findings including renal failure and hemolysis improve. In conclusion, regular cardiac evaluation including echocardiography, ECG, and cardiac enzymes are recommended after HSCT, and TA-TMA should be considered in patients with reduced EF after HSCT. Further cases are warranted to find the best management of myocardial ischemia caused by TA-TMA. 
Fig. 1 a Macroscopic examination reveals fibrosis on the anterior and posterior wall of the left ventricle. b, $\mathbf{c}$ Microscopic examination reveals fibrosis on the anterior and posterior wall of the left ventricle. $\mathbf{d}$ Microscopic examination reveals the organized thrombus in the distal part of the left anterior descending artery
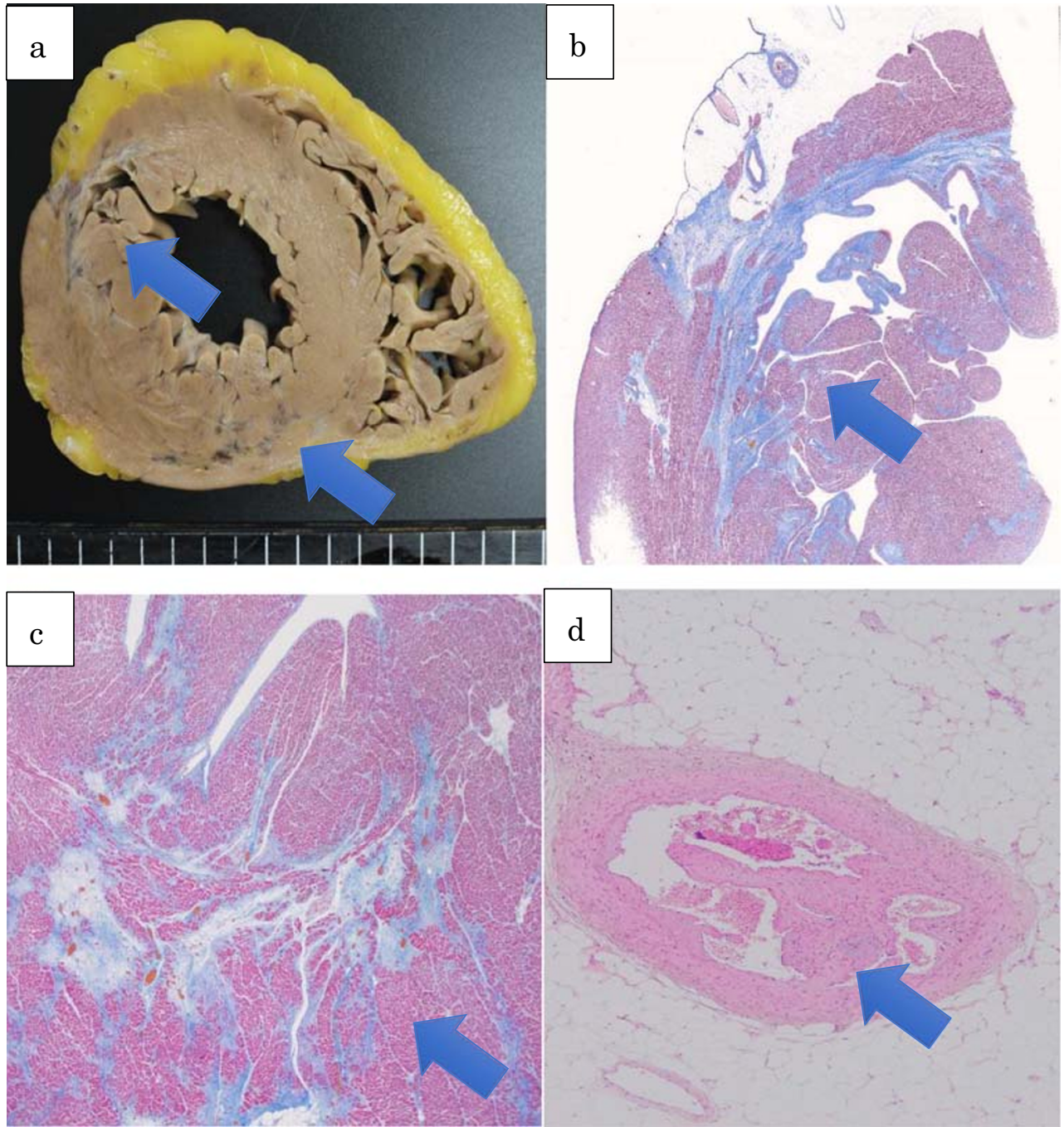

\section{Compliance with ethical standards}

Conflict of interest Mineo Kurokawa: Dr. Kurokawa received research funding from Novartis. The other authorsdeclare that they have no conflict of interest.

Ethical approval and informed consent Informed consent was obtained from the patient for inclusion in this case report.

Open Access This article is licensed under a Creative Commons Attribution 4.0 International License, which permits use, sharing, adaptation, distribution and reproduction in any medium or format, as long as you give appropriate credit to the original author(s) and the source, provide a link to the Creative Commons licence, and indicate if changes were made. The images or other third party material in this article are included in the article's Creative Commons licence, unless indicated otherwise in a credit line to the material. If material is not included in the article's Creative Commons licence and your intended use is not permitted by statutory regulation or exceeds the permitted use, you will need to obtain permission directly from the copyright holder. To view a copy of this licence, visit http://creativecommons.org/licenses/by/4.0/.

\section{References}

1. Khosla J, Yeh AC, Spitzer TR, Dey BR (2018) Hematopoietic stem cell transplant-associated thrombotic microangiopathy: current paradigm and novel therapies. Bone Marrow Transplant 53:129-137

2. Jodele S, Laskin BL, Dandoy CE, Myers KC, El-Bietar J, Davies SM et al (2015) A new paradigm: diagnosis and management of HSCTassociated thrombotic microangiopathy as multi-system endothelial injury. Blood Rev 29:191-204

3. Siami K, Kojouri K, Swisher KK, Selby GB, George JN, Laszik ZG (2008) Thrombotic microangiopathy after allogeneic hematopoietic stem cell transplantation: an autopsy study. Transplantation 85:22-28

4. Hertenstein B, Stefanic M, Schmeiser T, Scholz M, Göller V, Clausen M, Bunjes D, Wiesneth M, Novotny J, Kochs M (1994) Cardiac toxicity of bone marrow transplantation: predictive value of cardiologic evaluation before transplant. J Clin Oncol 12:998-1004

5. Tichelli A, Bhatia S, Socié G (2008) Cardiac and cardiovascular consequences after haematopoietic stem cell transplantation. Br J Haematol 142:11-26

Publisher's note Springer Nature remains neutral with regard to jurisdictional claims in published maps and institutional affiliations. 